\title{
Development and evaluation of pilot simulated patient centre: Learning from the experience
}

\author{
Bee Yean Low ${ }^{1}$ (D) Emily Farrow $^{2}$, Abigail Emtage ${ }^{3}$ (D) \\ ${ }^{1}$ School of Pharmacy, University of Nottingham Malaysia, Selangor, Malaysia \\ 2 School of Pharmacy, University of Nottingham, Nottingham, United Kingdom \\ ${ }^{3}$ Schrödinger, New York, United States
}

\author{
Keywords \\ Evaluation \\ Experience \\ Pharmacy education \\ Simulated patient
}

\author{
Correspondence \\ Bee Yean Low \\ School of Pharmacy \\ University of Nottingham Malaysia (UNM) \\ Jalan Broga \\ 43500 Semenyih, Selangor \\ Malaysia \\ BeeYean.Low@nottingham.edu.my
}

\begin{abstract}
Objectives: To compare the performance of paid actor-simulated patients: 1) before and after a simulated patient training programme aiming for programme enhancement; 2) to postgraduate/staff-simulated patients. Methods: Fifty-six student participants watched a series of video recordings of student pharmacist-paid actor-simulated patients role-playing and blindly assessed the performance of paid actor-simulated patients pre- and post-training using the Maastricht Assessment of Simulated Patients (MaSP). Seventy-three student participants compared the paid actor-simulated patients' performance to postgraduate/staff-simulated patients. Data collected were analysed using paired t-tests and independent t-tests, respectively. Results: There was a statistically significant improvement in the collated MaSP scores for paid actor-simulated patients' performance post-training in the authenticity of role-playing (mean score \pm standard deviation (SD): $2.61 \pm 0.30$ (Pre-training); $2.70 \pm 0.31$ (Posttraining), $p<0.05$ ) but not the quality of feedback. Similarly, paid actor-simulated patients performed better (in the authenticity of role-playing but not the quality of feedback) when compared to postgraduate/staff-simulated patients. Conclusions: Paid actor-simulated patients require improvement in providing quality feedback to students to enhance students' learning.
\end{abstract}

\section{Introduction}

A simulated patient is an individual who is coached to portray a patient in a simulated environment (Smithson et al., 2015). The simulation can be scripted (actor performs the work as directed) or improvisational (actor improvises the character around the key elements given) (Churchouse \& McCafferty, 2012). The teaching strategy of using simulated patients in pharmacy education has been viewed as valuable and beneficial (Raney, 2007; Rickles et al., 2009; Chin et al., 2014; Cravens et al., 2016), preferred by the learners (Grice et al., 2013), and can improve learners' confidence during their patient encounters and patient care (Branch, 2013; Maxwell et al., 2016; Zamami et al., 2016; Ong et al., 2018).

Role-playing is useful in developing pharmacy students' patient care skills, including communication skills, information gathering, and professionalism (Rao, 2011; Adrian et al., 2015; Fejzic \& Barker, 2015). The authenticity of role-playing and high-quality feedback are more important than uniformity and consistency of role-playing during educational sessions involving simulated patients (Wind et al., 2004). Therefore, simulated patients should be trained to be able to act authentically during roleplaying and be capable of providing high-quality feedback to students (Perera et al., 2009).

The three types of simulated patients most described in the pharmaceutical literature are community volunteers or paid actors, academic staff, and peers. Table I presents some of the benefits and limitations of each type of simulated patient (Gallimore et al., 2008; Smithson et al., 2015). The technique of role-playing with peers or staff members can provide a variety of active learning experiences for students (Barrows, 1993). The disadvantages of this approach include the lack of useful or critical feedback from other students (who are often peers or non-experts), inconsistent learning experiences 
resulting from wide variations in acting skills among participants, and difficulty pretending a known peer or faculty member is a "patient" (Rickles et al., 2009).

Table I: The benefits and disadvantages of each type of simulated patient (Gallimore et al., 2008; Smithson et al., 2015)

\begin{tabular}{|c|c|c|}
\hline $\begin{array}{l}\text { Type of } \\
\text { simulated } \\
\text { patient }\end{array}$ & Benefits & Disadvantages \\
\hline \multirow{6}{*}{$\begin{array}{l}\text { Paid actor/ } \\
\text { Community } \\
\text { volunteer }\end{array}$} & $\begin{array}{l}\text { Most authentic } \\
\text { (unfamiliar to students) }\end{array}$ & $\begin{array}{l}\text { High cost (if paid } \\
\text { actor) }\end{array}$ \\
\hline & $\begin{array}{l}\text { Increase understanding } \\
\text { of the pharmacy } \\
\text { profession in the } \\
\text { community }\end{array}$ & $\begin{array}{l}\text { Require more } \\
\text { training } \\
\text { consuming more } \\
\text { time and }\end{array}$ \\
\hline & \multirow{2}{*}{$\begin{array}{l}\text { Potential to improve the } \\
\text { perception of } \\
\text { pharmacists }\end{array}$} & resources \\
\hline & & $\begin{array}{l}\text { Limited feedback } \\
\text { on specific }\end{array}$ \\
\hline & \multirow{2}{*}{$\begin{array}{l}\text { Provide feedback from a } \\
\text { patient perspective }\end{array}$} & scenario details \\
\hline & & $\begin{array}{l}\text { Need to be } \\
\text { recruited so less } \\
\text { available }\end{array}$ \\
\hline \multirow[t]{4}{*}{ Academic staff } & Require less training & Intimidating \\
\hline & $\begin{array}{l}\text { Provide enhanced } \\
\text { feedback to students }\end{array}$ & $\begin{array}{l}\text { Unintentionally } \\
\text { prompt student }\end{array}$ \\
\hline & \multirow[t]{2}{*}{ Low cost } & $\begin{array}{l}\text { Wander from } \\
\text { script }\end{array}$ \\
\hline & & Low fidelity \\
\hline \multirow[t]{3}{*}{ Peer } & $\begin{array}{l}\text { The student patient } \\
\text { gains a deeper } \\
\text { understanding of the } \\
\text { patient case }\end{array}$ & $\begin{array}{l}\text { Induce anxiety } \\
\text { amongst the } \\
\text { student } \\
\text { Low fidelity }\end{array}$ \\
\hline & $\begin{array}{l}\text { Less training and low } \\
\text { cost }\end{array}$ & Limited feedback \\
\hline & Readily available & \\
\hline
\end{tabular}

Simulated patients are widely used in the performancebased teaching sessions of the medical and health sciences students. They are expected to provide feedback and have a positive impact on students' learning. However, the authenticity of role-playing and the quality of feedback provided by the simulated patients to students are rarely evaluated. Very little or no research to date has centred around an evaluation of the performance of the simulated patients from the learners' perspective. The present study aims to compare the paid actor-simulated patients' performance from the learners' perspective in the context of the authenticity of roleplaying and the quality of feedback 1 ) before and after a simulated patient training programme aiming for programme enhancement, and 2) to postgraduate/staffsimulated patients.

\section{Methods}

\section{Study design}

In this study, a half-day simulated patient training programme was designed to illustrate the key roles, skills, and techniques required for simulating a patient successfully. Table II details the presentation of the University's Simulated Patient Training Programme.

Table II: Powerpoint content of the half-day University's Simulated Patient Training Programme

\begin{tabular}{|c|c|c|c|}
\hline Slide & Description & Slide & Description \\
\hline 1 & $\begin{array}{l}\text { The University is } \\
\text { described to the } \\
\text { simulated patients }\end{array}$ & $2 \& 3$ & $\begin{array}{l}\text { Simulated patient } \\
\text { are detailed } \\
\text { (definition and } \\
\text { purpose) }\end{array}$ \\
\hline 4 & $\begin{array}{l}\text { How to be a } \\
\text { simulated patient is } \\
\text { detailed (registration } \\
\text { form, declaration of } \\
\text { consent) }\end{array}$ & 5 & FAQ section \\
\hline 6 & $\begin{array}{l}\text { Professional } \\
\text { standards required } \\
\text { for being a simulated } \\
\text { patient are detailed }\end{array}$ & $7-8$ & $\begin{array}{l}\text { Implicit bias is } \\
\text { detailed }\end{array}$ \\
\hline $9-10$ & $\begin{array}{l}\text { How to maintain } \\
\text { privacy and } \\
\text { confidentiality and } \\
\text { health and safety }\end{array}$ & $11-12$ & $\begin{array}{l}\text { Aims and objectives } \\
\text { of the University's } \\
\text { Simulated Patient } \\
\text { Training Programme }\end{array}$ \\
\hline $13-16$ & $\begin{array}{l}\text { The use of simulated } \\
\text { patients at the } \\
\text { University is detailed }\end{array}$ & 17,18 & $\begin{array}{l}\text { Types of role- } \\
\text { playing scenarios at } \\
\text { the University }\end{array}$ \\
\hline $19-23$ & $\begin{array}{l}\text { Details the scenarios } \\
\text { that the simulated } \\
\text { patients will be } \\
\text { performing }\end{array}$ & $24-27$ & $\begin{array}{l}\text { How to give } \\
\text { feedback to } \\
\text { students }\end{array}$ \\
\hline
\end{tabular}

Four paid actor-simulated patients were recruited into the University's Simulated Patient Training Programme. They were filmed in role-playing scenarios with four second-year pharmacy students, both before and after training. The four role-playing scenarios were responding to symptoms, medication history taking, prescription counselling, and device counselling. The four paid actor-simulated patients rotated around four different role-playing scenarios; however, only the video from the last scenario the paid actor-simulated patient enacted was chosen to be evaluated in this study, as detailed in Table III. There were eight video recordings in total, i.e. the pre- and post-training videos for each of the four paid actor-simulated patients in a role-playing scenario. Student participants then watched these series of video recordings of student pharmacist-paid actorsimulated patient role-playing and blindly assessed the 
performance of paid actor-simulated patients pre- and post-training in the context of the authenticity of the role-playing and the quality of feedback provided by paid actor-simulated patients using the Maastricht Assessment of Simulated Patients (MaSP) instrument (Wind et al., 2004).

Table III: The student pharmacist-paid actor-simulated patient role-playing scenarios

\begin{tabular}{|c|c|c|c|}
\hline $\begin{array}{l}\text { Simulated } \\
\text { patient }\end{array}$ & $\begin{array}{l}\text { The scenario used in the paid } \\
\text { actor-simulated patient's } \\
\text { evaluation }\end{array}$ & Pre-training scenario description & Post-training scenario description \\
\hline \multirow[t]{2}{*}{ One } & Prescription counselling* & The prescription was: & The prescription was: \\
\hline & & $\begin{array}{l}\text { Naproxen } 250 \text { mg tablets and Omeprazole } 20 \\
\text { mg capsules }\end{array}$ & Erythromycin $250 \mathrm{mg}$ tablets \\
\hline Two & Medication history taking* & $\begin{array}{l}\text { The patient was taking: Methotrexate } 15 \mathrm{mg} \\
\text { tablets, Folic acid } 5 \mathrm{mg} \text { tablets, Calcichew } \mathrm{D}_{3} \\
\text { chewable tablets, Lansoprazole } 15 \mathrm{mg} \\
\text { capsules, Carbomer } 0.2 \% \text { eye drops, } \\
\text { Paracetamol } 500 \mathrm{mg} \text { tablets }\end{array}$ & $\begin{array}{l}\text { The patient was taking: Aspirin } 75 \mathrm{mg} \\
\text { tablets, Bisoprolol } 5 \mathrm{mg} \text { tablets, Ramipril } \\
2.5 \mathrm{mg} \text { capsules, Atorvastatin } 80 \mathrm{mg} \\
\text { tablets, GTN } 400 \text { microgram spray, } \\
\text { Migraleve } \\
\text { (allergic to simvastatin) }\end{array}$ \\
\hline Three & Device counselling* & $\begin{array}{l}\text { The patient had been prescribed Ventolin } \\
\text { Evohaler (salbutamol), he/she had never had } \\
\text { it before and needed counselling on how to } \\
\text { use it. }\end{array}$ & $\begin{array}{l}\text { The patient had been prescribed } \\
\text { Tiotropium Handihaler for his/her asthma } \\
\text { and had never used it before and needed } \\
\text { counselling on how to use it. }\end{array}$ \\
\hline Four & Responding to symptoms* & $\begin{array}{l}\text { The patient had symptoms of heartburn and } \\
\text { have had it before. The patient needed to } \\
\text { explain his/her symptoms to the student } \\
\text { pharmacist, for the student pharmacist to } \\
\text { recommend a suitable course of action. }\end{array}$ & $\begin{array}{l}\text { The patient had heartburn symptoms } \\
\text { which followed from eating a large meal. } \\
\text { The patient needed to tell the student } \\
\text { pharmacist this information for the } \\
\text { student pharmacist to recommend a } \\
\text { suitable course of action. }\end{array}$ \\
\hline
\end{tabular}

*Note each paid actor-simulated patient performed all the role-playing scenarios; however they were only evaluated performing the one indicated above

After paid actor-simulated patients went through the University's Simulated Patient Training Programme, their performance was compared to the postgraduate/staff-simulated patients (simulated patients type commonly used in the timetabled teaching and learning sessions requiring patient's interaction at the University) during the timetabled teaching and learning sessions. Pharmacy students were divided into two groups to have allocated either a paid actor-simulated patient or a postgraduate/staffsimulated patient during the timetabled teaching and learning sessions requiring simulated patients at the University. It should be noted that postgraduate/staffsimulated patients were provided with training (in terms of safety and giving feedback) before helping with the timetabled teaching and learning sessions, but their training was not as extensive or recent as the training given to the paid actor-simulated patients.

\section{Maastricht Assessment of Simulated Patients (MaSP)}

The Maastricht Assessment of Simulated Patients (MaSP) consisted of 20 statements: items 1-10 relating to 'authenticity of role-play' and items $11-20$ relating to 'quality of feedback'. The instrument utilised a 4-point
Likert scale for assessors to respond to each statement regarding the simulated patient's performance (4=complete agreement and 1=complete disagreement) except for items 10 and 11 (both of which are dichotomous questions) (Wind et al., 2004). Item 10 and 11 of the MaSP were not included in the calculation of mean scores for the 'authenticity of roleplay' and 'quality of feedback' in this study. The benefit of a 4-point Likert scale is that there is no option for a 'neutral' answer, allowing for more specific conclusions to be made. Item 21 on the MaSP instrument enables assessors to provide a general mark out of 10 for the simulated patient's performance.

\section{Study population}

The student participants of this study were first- and second-year pharmacy students at the University. No other exclusion criteria were set. Student participants were recruited from a mixture of notifications during timetabled teaching and learning sessions and emails (sent from the investigator to the MPharm Year 1 and Year 2 cohorts). Two methods of recruitment were employed in the hope of maximising participation. Student participants were not paid; however, they 
received a small token of appreciation, such as a mug or keychain, for taking part. All student participants were given full details of the study both verbally and in written form before taking part. Each student participant received a participant information sheet and a research privacy notice to read before signing a consent form agreeing to take part. Each student participant was free to withdraw from the study at any time and was not disadvantaged for not participating. The Science \& Engineering Research Ethics Committee (SEREC) at the University granted the ethical application and approval.

\section{Data analysis}

Student participants' responses were compiled and a second independent individual checked all data entered. Any disagreement in the data entry was reconciled and resolved. A paired t-test was calculated for each of the four paid actor-simulated patients and the collated MaSP scores for paid actor-simulated patients' performance in the context of the authenticity of role-playing and quality of feedback. An independent sample t-test was used to compare the performance of the paid actor-simulated patients and the simulated patient type commonly used at the University, namely the postgraduate/staff-simulated patients. The alpha value was set at 0.05 and a confidence interval of $95 \%$. All data were analysed using the Statistical Package for Social Sciences (SPSS) version 26.

\section{Results}

The recruitment process managed to engage fifty-six pharmacy students to participate in the video recordings viewing study comparing the performance of the paid actor-simulated patients pre- and posttraining of the University's Simulated Patient Training Programme. Seventy-three pharmacy students were recruited to participate in the comparison study between paid actor-simulated patients and postgraduate/staff-simulated patients.

Fifty-six pharmacy student participants reviewed the eight role-playing scenarios, four for each pre- and post-training using the MaSP instrument. The results of this study revealed that there was a statistically significant improvement in the collated MaSP scores for paid actor-simulated patients with regards to the authenticity of the role-playing post-training (mean score \pm standard deviation (SD): $2.61 \pm 0.30$ Pretraining; $2.70 \pm 0.31$ Post-training, $p<0.05)$. However, there was no statistically significant difference in the performance of the collated MaSP scores for paid actor-simulated patients with regards to the quality of the feedback pre- and post-training (mean score \pm SD: $2.83 \pm 0.32$ Pre-training; $2.82 \pm 0.34$ Post-training, $p>0.05)$. When considering individual paid actorsimulated patients, there was a statistically significant improvement for paid actor-simulated patient one $(p=0.001)$ and paid actor-simulated patient three $(p=0.008)$ for the authenticity of role-playing. The mean scores for the authenticity of role-playing for paid actor-simulated patient two and paid actor-simulated patient four increased post-training, but these were not statistically significant $(p>0.05)$. In terms of the quality of feedback, paid actor-simulated patients one, three, and four all showed an increase in the mean scores attained for the quality of feedback, but these were not of statistical significance. The mean scores for the quality of feedback for paid actor-simulated patient two showed a statistically significant decrease posttraining $(p=0.001)$. This result was in the opposite direction as the mean scores dropped from $2.77 \pm 0.30$ pre-training to $2.57 \pm 0.32$ post-training, indicating the student participants judged the feedback provided to be of lower quality post-training.

Table IV presents the mean scores and $p$-values relating to the authenticity of role-playing for each paid actorsimulated patient and the collated paid actor-simulated patients. Table $\mathrm{V}$ presents the mean scores and $p$ values relating to the quality of feedback for each paid actor-simulated patient and the collated paid actorsimulated patients. Table VI shows the mean scores received by each paid actor-simulated patient for each question on the MaSP instrument (omitting items 10 and 11), pre- and post-training.

When the performance of the paid actor-simulated patients was compared to the postgraduate/staffsimulated patients in the timetabled teaching and learning sessions, paid actor-simulated patients performed significantly better than postgraduate/staffsimulated patients concerning the authenticity of roleplaying $(p<0.05)$ but not the quality of the feedback $(p>0.05)$. Seventy-three pharmacy students participated in this study, comparing the performance of paid actor-simulated patients against the postgraduate/staff-simulated patients.

Table VII shows the comparison of mean scores and $p$ values relating to the authenticity of role-playing and quality of feedback obtained by the paid actorsimulated patients and postgraduate/staff-simulated patients. 
Table IV: Pre- and post-training mean scores and p-values for the authenticity of role-playing from the students' assessment of each and collated paid actor-simulated patients using the MaSP instrument (items 1-9 of the MaSP instrument)

\begin{tabular}{|c|c|c|c|c|c|}
\hline \multicolumn{6}{|c|}{ Authenticity of role-playing } \\
\hline & \multicolumn{2}{|r|}{ Pre-training } & \multicolumn{2}{|c|}{ Post-training } & \multirow[b]{2}{*}{$p$-value } \\
\hline & Mean & Standard deviation & Mean & Standard deviation & \\
\hline \multicolumn{6}{|c|}{ Paid actor-simulated patient one } \\
\hline Year one & 2.64 & 0.28 & 2.78 & 0.23 & $0.047^{*}$ \\
\hline Year two & 2.51 & 0.39 & 2.78 & 0.29 & $0.007^{*}$ \\
\hline Year one and two & 2.59 & 0.33 & 2.78 & 0.25 & $0.001^{*}$ \\
\hline \multicolumn{6}{|c|}{ Paid actor-simulated patient two } \\
\hline Year one & 2.44 & 0.25 & 2.51 & 0.26 & 0.230 \\
\hline Year two & 2.48 & 0.36 & 2.40 & 0.36 & 0.507 \\
\hline Year one and two & 2.46 & 0.29 & 2.47 & 0.31 & 0.879 \\
\hline \multicolumn{6}{|c|}{ Paid actor-simulated patient three } \\
\hline Year one & 2.57 & 0.23 & 2.70 & 0.26 & $0.038^{*}$ \\
\hline Year two & 2.71 & 0.20 & 2.78 & 0.23 & 0.057 \\
\hline Year one and two & 2.62 & 0.23 & 2.73 & 0.25 & $0.008^{*}$ \\
\hline \multicolumn{6}{|c|}{ Paid actor-simulated patient four } \\
\hline Year one & 2.79 & 0.20 & 2.78 & 0.30 & 0.841 \\
\hline Year two & 2.80 & 0.27 & 2.87 & 0.27 & 0.377 \\
\hline Year one and two & 2.79 & 0.23 & 2.81 & 0.29 & 0.652 \\
\hline \multicolumn{6}{|c|}{ Collated paid actor-simulated patients } \\
\hline Year one & 2.61 & 0.27 & 2.69 & 0.28 & $0.008^{*}$ \\
\hline Year two & 2.62 & 0.34 & 2.71 & 0.34 & 0.067 \\
\hline Year one and two & 2.61 & 0.30 & 2.70 & 0.31 & $0.001 *$ \\
\hline
\end{tabular}

Table V: Pre- and post-training mean scores and p-values for quality of feedback from the students' assessment of each and collated paid actor-simulated patients using the MaSP instrument (items 12-20 of the MaSP instrument)

\begin{tabular}{|c|c|c|c|c|c|}
\hline \multicolumn{6}{|c|}{ Quality of feedback } \\
\hline & \multicolumn{2}{|r|}{ Pre-training } & \multicolumn{2}{|c|}{ Post-training } & \multirow[b]{2}{*}{$p$-value } \\
\hline & Mean & Standard deviation & Mean & Standard deviation & \\
\hline \multicolumn{6}{|c|}{ Paid actor-simulated patient one } \\
\hline Year one & 2.84 & 0.32 & 2.89 & 0.22 & 0.478 \\
\hline Year two & 2.86 & 0.31 & 2.90 & 0.31 & 0.671 \\
\hline Year one and two & 2.85 & 0.32 & 2.89 & 0.26 & 0.422 \\
\hline \multicolumn{6}{|c|}{ Paid actor-simulated patient two } \\
\hline Year one & 2.71 & 0.28 & 2.58 & 0.25 & 0.054 \\
\hline Year two & 2.86 & 0.32 & 2.56 & 0.40 & 0.012 \\
\hline Year one and two & 2.77 & 0.30 & 2.57 & 0.32 & $0.001^{*}$ \\
\hline \multicolumn{6}{|c|}{ Paid actor-simulated patient three } \\
\hline Year one & 2.78 & 0.27 & 2.82 & 0.25 & 0.545 \\
\hline Year two & 2.95 & 0.20 & 2.97 & 0.35 & 0.813 \\
\hline Year one and two & 2.85 & 0.26 & 2.88 & 0.30 & 0.534 \\
\hline \multicolumn{6}{|c|}{ Paid actor-simulated patient four } \\
\hline Year one & 2.82 & 0.38 & 2.93 & 0.36 & 0.273 \\
\hline Year two & 2.94 & 0.38 & 2.99 & 0.28 & 0.616 \\
\hline Year one and two & 2.87 & 0.38 & 2.95 & 0.33 & 0.228 \\
\hline \multicolumn{6}{|c|}{ Collated paid actor-simulated patients } \\
\hline Year one & 2.79 & 0.32 & 2.80 & 0.30 & 0.657 \\
\hline Year two & 2.90 & 0.31 & 2.85 & 0.38 & 0.390 \\
\hline Year one and two & 2.83 & 0.32 & 2.82 & 0.34 & 0.807 \\
\hline
\end{tabular}


Table VI: Pre- and post-training mean scores comparison from the students' assessment of each paid actorsimulated patient for each question in the sections of the authenticity of role-playing and quality of feedback in the MaSP instrument (omitting items 10 and 11)

\begin{tabular}{|c|c|c|c|c|c|c|c|c|}
\hline \multirow[t]{2}{*}{ Mean score } & \multicolumn{4}{|c|}{ Pre-training } & \multicolumn{4}{|c|}{ Post-training } \\
\hline & One* & Two* & Three* & Four* & One* & Two* & Three* & Four* \\
\hline Q1: Simulated patient appears authentic & 3.0 & 2.6 & 2.9 & 3.1 & 3.3 & 2.7 & 3.1 & 3.3 \\
\hline Q2: Simulated patient might be a real patient & 2.3 & 2.4 & 2.6 & 2.8 & 2.9 & 2.4 & 2.9 & 3.0 \\
\hline Q3: Simulated patient is clearly role-playing & 2.9 & 2.7 & 2.6 & 2.6 & 2.6 & 2.6 & 2.6 & 2.6 \\
\hline $\begin{array}{l}\text { Q4: Simulated patient appears to withhold information } \\
\text { unnecessarily }\end{array}$ & 2.0 & 1.8 & 1.7 & 1.8 & 1.8 & 1.7 & 1.6 & 1.8 \\
\hline Q5: Simulated patient stays in his/her role all the time & 3.1 & 3.0 & 3.3 & 3.2 & 3.4 & 3.1 & 3.3 & 3.4 \\
\hline Q6: Simulated patient is challenging/testing the student & 2.3 & 2.1 & 2.4 & 3.0 & 2.9 & 2.1 & 2.8 & 3.1 \\
\hline $\begin{array}{l}\text { Q7: Simulated patient simulates physical complaints } \\
\text { unrealistically }\end{array}$ & 2.1 & 1.9 & 1.7 & 1.7 & 1.8 & 1.9 & 1.8 & 1.7 \\
\hline Q8: Simulated patient's appearance fits the role & 2.8 & 2.9 & 3.1 & 3.3 & 3.1 & 2.9 & 3.2 & 3.3 \\
\hline Q9: Simulated patient answers questions in a natural manner & 2.8 & 2.6 & 3.1 & 3.3 & 3.3 & 2.7 & 3.2 & 3.2 \\
\hline Q12: Simulated patient stimulates student to ask questions & 2.4 & 2.3 & 2.5 & 2.5 & 2.4 & 2.2 & 2.6 & 2.6 \\
\hline $\begin{array}{l}\text { Q13: I can judge from the reactions of the simulated patient } \\
\text { whether he/she listens to the student or not }\end{array}$ & 3.3 & 3.1 & 3.4 & 3.3 & 3.4 & 3.0 & 3.4 & 3.4 \\
\hline $\begin{array}{l}\text { Q14: Simulated patient communicates how he/she felt during } \\
\text { the consultation }\end{array}$ & 3.3 & 3.3 & 3.3 & 3.3 & 3.3 & 2.9 & 3.4 & 3.5 \\
\hline Q15: Simulated patient gives feedback about medical issues & 2.6 & 2.4 & 2.5 & 3.2 & 2.7 & 2.4 & 2.5 & 3.2 \\
\hline Q16: Simulated patient gives examples from the consultation & 3.0 & 2.8 & 2.9 & 3.1 & 3.1 & 2.6 & 3.0 & 3.3 \\
\hline $\begin{array}{l}\text { Q17: Simulated patient speaks about his/her role in the first } \\
\text { person (I) }\end{array}$ & 2.7 & 3.2 & 3.1 & 3.2 & 3.1 & 3.0 & 2.9 & 3.0 \\
\hline Q18: Simulated patient gives constructive criticism & 2.9 & 2.6 & 2.8 & 3.2 & 2.8 & 2.5 & 3.1 & 3.1 \\
\hline Q19: Simulated patient compares student with other students & 1.8 & 1.7 & 1.4 & 1.4 & 1.4 & 1.3 & 1.4 & 1.4 \\
\hline Q20: Simulated patient is friendly to the student & 3.6 & 3.4 & 3.6 & 2.6 & 3.7 & 3.2 & 3.6 & 3.1 \\
\hline
\end{tabular}

* Paid actor-simulated patient

Table VII: Comparison of paid actor-simulated patients and postgraduate/staff-simulated patients' mean scores and p-values for the authenticity of role-playing (items 1-9 of the MaSP instrument) and quality of feedback (items 12-20 of the MaSP instrument) from the students' assessment using the MaSP instrument in the timetabled teaching and learning sessions

\begin{tabular}{|c|c|c|c|c|c|}
\hline & \multicolumn{2}{|c|}{ Paid actor-simulated patients } & \multicolumn{2}{|c|}{ Postgraduate/staff-simulated patients } & \multirow[b]{2}{*}{$p$-value } \\
\hline & Mean & Standard deviation & Mean & Standard deviation & \\
\hline \multicolumn{6}{|c|}{ Authenticity of role-playing } \\
\hline Year one & 2.82 & 0.28 & 2.64 & 0.23 & $0.04^{*}$ \\
\hline Year two & 2.89 & 0.19 & 2.68 & 0.28 & $0.02 *$ \\
\hline \multicolumn{6}{|c|}{ Quality of feedback } \\
\hline Year one & 2.73 & 0.49 & 2.74 & 0.35 & 0.92 \\
\hline Year two & 2.81 & 0.44 & 2.76 & 0.47 & 0.74 \\
\hline
\end{tabular}

Statistical significant results are marked by an *

\section{Discussion}

Paid actor-simulated patients' performance before and after University's Simulated Patient Training Programme

The results obtained in this study can be interpreted in two challenging ways. The University's Simulated Patient Training Programme was successful as there was a statistically significant improvement in the collated paid actor-simulated patients' performance post-training in the context of the authenticity of roleplaying, although not in the context of quality of feedback. On the other hand, the results obtained indicated that it might not be a true reflection of the University's Simulated Patient Training Programme but 
tailored support should be provided to the individual paid actor-simulated patient.

When evaluating the video recordings of the student pharmacist-paid actor-simulated patient role-playing, only the last scenario enacted by the paid actorsimulated patient was chosen to be evaluated by student participants. The objective was to ensure the performance of both the student pharmacists and the paid actor-simulated patients were not affected by the anxiety of participation which could potentially affect their role-playing and, subsequently, their performance.

\section{Lessons learned from the student participants' evaluation of student pharmacist-paid actor- simulated patients' role-playing scenarios}

Paid actor-simulated patients require improvement in providing quality feedback to students to enhance students' learning. However, there is limited information on how to train simulated patients to provide high-quality feedback. One method reported by Perera and colleagues (2009) was to use 'experienced simulated patients' to train new simulated patients. However, since paid actorsimulated patients were a new introduction to the University, implementing this would have involved the recruitment of simulated patients from other pharmacy and medical schools in the country, making it less feasible. Therefore, the areas where paid actorsimulated patients performed poorly were studied and highlighted to enhance the quality of feedback of the paid actor-simulated patients to the students.

The areas where paid actor-simulated patients performed poorly and required improvement to ensure quality feedback provided to students were 1) stimulating students to ask questions; 2) providing feedback from the patient's perspective; 3) providing constructive criticism. Peer-reviewed findings stated that students benefit from the exercise if they are actively engaged with the simulated patient (Lloyd et al., 2018). Austin and colleagues (2006) had incorporated the simulated patients' feedback from the patient's perspective into building the teaching and assessment cases for students. Students valued the use of this approach, which improved their pharmaceutical care skills and helped them to better understand the psychosocial needs of patients in practice. Therefore, paid actor-simulated patients should provide feedback from the patient's perspective, so the students gain a deeper understanding of how they have made patients feel during the consultation. This type of feedback also identified areas of weakness regarding the students' consultation skills, allowing them to reflect and improve. Feedback provided to students should be constructive and not overly critical or demoralising
(Melluish et al., 2007; Bouter et al., 2013). Students' weaknesses were not just highlighted but delivered in a way the student feels supported, allowing them to reflect and improve their performance in the future. One method of doing this was educating simulated patients on feedback frameworks such as the "Pendleton rules of feedback", as reported by James and co-workers (2001). Chowdhury and Kalu (2004) stated that the focus of this type of feedback was to ensure they were constructive, and they added that the positives should be delivered first, followed by the areas students could improve.

The other areas where paid actor-simulated patients performed poorly were 1) not comparing between students; 2) not giving examples from the consultation; 3) not giving feedback about medical issues. It could be argued that giving students examples of good consultation techniques demonstrated by their peers may be beneficial; however, the other school of thought felt that feedback should be tailored to the individual involved in the scenario and comparisons between students served a limited purpose. Further investigation is needed on how the comparison is made as it is likely to be vital, and the opinions of the students should be considered. The paid actor-simulated patients are lay individuals with limited pharmacy knowledge, and it is not expected that they give feedback relating to specific case details since this is the role of the academic observing the scenario. As such, this should be communicated to the students before the teaching and learning sessions.

On the other hand, the results from the study described herein were encouraging in the aspect that paid actorsimulated patients actively listened to the student during the role-playing and were friendly to the students. These reassuring experiences are expected to positively impact students' learning.

\section{Comparison between paid actor-simulated patients and postgraduate/staff-simulated patients}

The findings from this study and the literature agreed that, overall, paid actor-simulated patients were superior concerning the authenticity of role-playing. Although there was not a statistically significant difference in the quality of feedback, analysing the mean scores has shown that paid actor-simulated patients performed marginally better. Therefore, it can be concluded from the results of this study that the paid actor-simulated patients were the better performing type of simulated patients and may contribute more to pharmacy student professional development. However, further research is needed to confirm this finding and examine the types of simulated 
patients that specifically impact student skill development.

Smithson and colleagues (2015) reported that unfamiliarity of the simulated patients to the students contributed to increasing the authenticity of the roleplaying. This finding was supported by a study undertaken by Gallimore and coworkers (2008), who found that students felt more prepared for real-patient encounters when simulated patients were used due to the highfidelity role-playing. The results from this study were in agreement with the above findings to a certain extent. The second-year pharmacy students had encountered the postgraduate/staff-simulated patients before, and perhaps, as a consequence of this, they deemed the paid actor-simulated patients significantly more authentic than the postgraduate/staff-simulated patients $(p<0.05)$. Nevertheless, first-year pharmacy students had not been exposed to either type of simulated patients (before this study) and yet perceived paid actor-simulated patients to be more authentic than the postgraduate/staff-simulated patients $(p<0.05)$, suggesting that paid actor-simulated patients were superior to postgraduate/staff-simulated patients as results of the University's Simulated Patient Training Programme, although an exclusive correlation cannot be made. Despite this result, it is worth noting that even for first-year pharmacy students, factors such as the perceived age of the simulated patient or whether the individual was perceived as being a postgraduate student/staff or not may have influenced these findings.

The comparison of the paid actor-simulated patients and postgraduate/staff-simulated patients revealed no statistically significant difference between the two types of simulated patients in terms of the quality of feedback, indicating that the University's Simulated Patient Training Programme should be enhanced with elements of quality feedback to students to ensure the use of simulated patients benefits students learning.

\section{Limitations}

Items 10 and 11 of the MaSP instrument were presented as scaled-response questions in this study. These should have been presented as dichotomous questions, as in the original MaSP instrument. However, the responses from items 10 and 11 of the MaSP instrument were excluded in the data analysis, similar to the original MaSP instrument.

The negative statements on the MaSP instrument were not re-coded, which could limit the comparability of the authenticity and feedback mean scores. However, previous studies have analysed the results without recoding, indicating these results can still be discussed in the context of other current literature.

\section{Ways forward}

The simulated patients can self-assess and peer-assess the recorded videos of their performance. The positives and negatives of the performances can be discussed, facilitated by a staff member. Perera and colleagues (2009) showed this approach has proven to be beneficial in terms of improving the simulated patients' performance, and it should be incorporated into any future simulated patients' training.

A qualitative approach should be undertaken to gain a deeper understanding of the views of the pharmacy students. It will also allow students to elaborate on the responses they provided in the questionnaire and have their say in what they value in terms of simulated patients' performance.

More data is needed for a conclusion to be made on the type of simulated patient most beneficial for improving students' skills development. One method of doing this is to conduct a study utilising various types of simulated patients for the student pharmacist-simulated patient's encounters and measuring students' performance or the accomplishment of specific professional competency skills after the consultation and feedback. This process takes off the onus of student perception and would allow for a skill or performance-based comparison with a certain type of simulated patient.

\section{Conclusions}

The use of simulated patients is useful in developing the professional skills of pharmacy students, providing that the portrayal of simulated patients is authentic, and simulated patients provide quality feedback to the students. It is therefore essential for the simulated patients' performance to be assessed to assure quality education is delivered, which contributes positively to students' development.

Analysis of the results of this study has highlighted areas the simulated patients' performance could be improved, particularly concerning the quality of feedback the simulated patients provide. The improved performance of the simulated patients regarding the authenticity of roleplaying and, in particular, the quality of feedback provided to the students will eventually positively impact the skills development of the pharmacy students.

\section{Declaration of interest statement}

This work was carried out in the School of Pharmacy, University of Nottingham Malaysia, Malaysia. Ms. Emily Farrow was a third-year pharmacy exchange student at 
the University of Nottingham Malaysia during the study period. Dr. Abigail Emtage was an Assistant Professor at the University of Nottingham Malaysia at the start of the study period. All authors declared no conflict of interest. The materials and contents presented in this manuscript were used in the dissertation submitted for a research project module of the third year MPharm (Hons) student (Ms. Emily Farrow).

\section{Funding}

This study was funded by the University of Nottingham Malaysia Teaching and Learning Funding Scheme 2019.

\section{References}

Adrian, J. A. L., Zeszotarski, P., \& Ma, C. (2015). Developing pharmacy student communication skills through roleplaying and active learning. American Journal of Pharmaceutical Education, 79(3), Article 44. https://doi.org/10.5688/ajpe79344

Austin, Z., Gregory, P., \& Tabak, D. (2006). Simulated patients vs. standardized patients in objective structured clinical examinations. American Journal of Pharmaceutical Education, 70(5), Article 119

Barrows, H. S. (1993). An overview of the uses of standardized patients for teaching and evaluating clinical skills. Academic Medicine, 68(6), 443-451. https://doi.org/10.1097/00001888-199306000-00002

Bouter, S., Van Weel-Baumgarten, E., \& Bolhuis, S. (2013). Construction and validation of the Nijmegen evaluation of the simulated patient (NESP): Assessing simulated patients' ability to role-play and provide feedback to students. Academic Medicine, 88(2), 253-259.

https://doi.org/10.1097/ACM.0b013e31827c0856

Branch, C. (2013). Pharmacy students' learning and satisfaction with high-fidelity simulation to teach druginduced dyspepsia. American Journal of Pharmaceutical Education, 77(2), Article 30.

https://doi.org/10.5688/ajpe77230

Chin, K. L., Yap, Y. L., Lee, W. L., \& Soh, Y. C. (2014). Comparing effectiveness of high-fidelity human patient simulation vs case-based learning in pharmacy education. American Journal of Pharmaceutical Education, 78(8), Article 153. https://doi.org/10.5688/ajpe788153

Chowdhury, R. R., \& Kalu, G. (2004). Learning to give feedback in medical education. The Obstetrician \& Gynaecologist, 6(4), 243-247.

https://doi.org/10.1576/toag.6.4.243.27023

Churchouse, C., \& McCafferty, C. (2012). Standardized patients versus simulated patients: is there a difference? Clinical Simulation in Nursing, 8(8), e363-e365. https://doi.org/10.1016/j.ecns.2011.04.008
Cravens, M. G., Benner, K., Beall, J., Worthington, M., Denson, B., Youngblood, A. Q., Lynn Zinkan, J., \& Tofil, N. M. (2016). Knowledge gain of pharmacy students and pharmacists comparing simulation versus traditional learning methodology. Journal of Pediatric Pharmacology and Therapeutics, 21(6), 476-485.

https://doi.org/10.5863/1551-6776-21.6.476

Fejzic, J., \& Barker, M. (2015). Implementing simulated learning modules to improve students' pharmacy practice skills and professionalism. Pharmacy Practice, 13(3), 583590. https://doi.org/10.18549/PharmPract.2015.03.583

Gallimore, C., George, A. K., \& Brown, M. C. (2008). Pharmacy students' preferences for various types of simulated patients. American Journal of Pharmaceutical Education, 72(1), Article 4

Grice, G. R., Wenger, P., Brooks, N., \& Berry, T. M. (2013). Comparison of patient simulation methods used in a physical assessment course. American Journal of Pharmaceutical Education, 77(4), Article 77. https://doi.org/10.5688/ajpe77477

James, D., Nastasic, S., Davies, J.G. \& Horne, R. (2001). The design and evaluation of a simulated-patient teaching programme to develop the consultation skills of undergraduate pharmacy students. Pharmacy World and Science, 23(6), 212-216.

https://doi.org/10.1023/A:1014512323758

Lloyd, M., Watmough, S., \& Bennett, N. (2018). Simulationbased training: applications in clinical pharmacy. Clinical Pharmacist, 10(9), 1-20.

https://doi.org/10.1211/CP.2018.20205302

Maxwell, W. D., Mohorn, P. L., Haney, J. S., Phillips, C. M., Kevin Lu, Z., Clark, K., Corboy, A., \& Ragucci, K. R. (2016). Impact of an advanced cardiac life support simulation laboratory experience on pharmacy student confidence and knowledge. American Journal of Pharmaceutical Education, 80(8), Article 140. https://doi.org/10.5688/ajpe808140

Melluish, S., Crossley, J., \& Tweed, A. (2007). An evaluation of the use of simulated patient role-plays in the teaching and assessment of clinical consultation skills in clinical psychologists' training. Psychology Learning \& Teaching, 6(2), 104-113. https://doi.org/10.2304/plat.2007.6.2.104

Ong, C. L., Kane-Gill, S. L., Kobulinsky, L. R., Hon, J. S., Kong, M. C., \& Seybert, A. L. (2018). Evaluation of pharmacist satisfaction with simulation-based learning in Singapore. Currents in Pharmacy Teaching and Learning, 10(10), 14141418. https://doi.org/10.1016/j.cptl.2018.07.004

Perera, J., Perera, J., Abdullah, J., \& Lee, N. (2009). Training simulated patients: evaluation of a training approach using self-assessment and peer/tutor feedback to improve performance. BMC Medical Education, 9, Article number 37. https://doi.org/10.1186/1472-6920-9-37

Raney, E. C. (2007). Assessment of anticoagulation management in a simulated ambulatory care clinic. American Journal of Pharmaceutical Education, 71(5), Article 97

Rao, D. (2011). Skills development using role-play in a firstyear pharmacy practice course. American Journal of 
Pharmaceutical Education, 75(5), Article 84. https://doi.org/10.5688/ajpe75584

Rickles, N. M., Tieu, P., Myers, L., Galal, S., \& Chung, V. (2009). The impact of a standardized patient program on student learning of communication skills. American Journal of Pharmaceutical Education, 73(1), Article 4

Smithson, J., Bellingan, M., Glass, B., \& Mills, J. (2015). Standardized patients in pharmacy education: an integrative literature review. Currents in Pharmacy Teaching and Learning, 7(6), 851-863.

https://doi.org/10.1016/j.cptl.2015.08.002

Wind, L. A., Van Dalen, J., Muijtjens, A. M. M., \& Rethans, J. (2004). Assessing simulated patients in an educational setting: the MaSP (Maastricht Assessment of Simulated Patients). Medical Education, 38, 39-44

Zamami, Y., Imai, T., Imanishi, M., Takechi, K., Shiraishi, N., Koyama, T., Sagara, H., Shiino, Y., Sendo, T., \& Ishizawa, K. (2016). Evaluation of pharmaceutical lifesaving skills training oriented pharmaceutical intervention. Journal of

Pharmaceutical Health Care and Sciences, 2(1), Article 21. https://doi.org/10.1186/s40780-016-0054-7 